\title{
The Effect of Flipped Classroom by Near Peer Education (FC by NPE) on Patient Safety Knowlege Retention in Nursing and Midwifery Students: A Solomon Four-Group Design
}

Sima poormahdi golaki

MS Student of Nursing, Student Research Committee, Faculty of nursing and midwifery Bushehr University of Medical Sciences, Bushehr, Iran

Farahnaz Kamali

PhD of Medical Education, Nursing and Midwifery Faculty. Bushehr University of Medical Sciences.

\section{Razieh Bagherzadeh}

PhD of Reproductive Health, Department of Midwifery, Nursing and Midwifery Faculty. Bushehr University of Medical Sciences, Bushehr, Iran.

\section{Fatemeh Hajinejad}

MS in Nursing, Nursing and Midwifery Faculty. Bushehr University of Medical Sciences, Bushehr, Iran.

Hakimeh Vahedparast ( $\sim$ h.vahedparast@bpums.ac.ir)

PhD of Nursing, Department of Nursing and Midwifery Faculty. Bushehr University of Medical Sciences, Salmanefarsi Blvd, Bushehr. Iran

\section{Research Article}

Keywords: Flipped Classroom, Near-Peer Education, Patient Safety, Nursing, Midwifery, Students, Knowledge Retention

Posted Date: February 8th, 2021

DOl: https://doi.org/10.21203/rs.3.rs-150129/v1

License: (c) (i) This work is licensed under a Creative Commons Attribution 4.0 International License. Read Full License 


\section{Abstract}

Introduction: Selecting an appropriate teaching method is one of the key stages in education. This study was to the effect of FC by NPE on patient safety knowledge retention in nursing and midwifery students.

Methods: This randomized controlled trial, using the Solomon design, was conducted in 2019 on an 82nursing and midwifery students enrolled from Bushehr nursing and midwifery school. The samples were then allocated to four groups via block randomization. The samples in both intervention groups studied the educational content online for two weeks and subsequently attended the FC by NPE. Both control groups merely received the conventional methods. The posttest was also taken from the four study groups immediately and two months after education.

Results: The posttest mean scores of knowledge in both intervention groups was homogeneous $(\mathrm{p}=0.1)$ and higher than those in the control groups $(\mathrm{p}<0.05)$. The changes in the mean scores posttest in the intervention and follow-up it did not establish a statistically significant difference between the four study groups $(p=0.130, F=1.941)$.

Conclusion: The use of the FC by NPE could increase the knowledge mean scores, but, it failed to affect knowledge retention. Given the infancy of this pedagogical approach, further studies are needed to investigate its effects on various learning outcomes.

\section{Background}

Innovations and rapid changes in socioeconomic, political, and technological domains have mostly challenged medical education with their own complexities. They have additionally made the roles of medical science educators much heavier and more complicated than ever. Moreover, it no longer seems possible to lead medical students towards progress through conventional methods [1].

In the present era, selecting the most appropriate teaching methods is one of the strategies adopted by teachers to augment the quality of their education according to students' specific goals and conditions [2]. Using new methods of teaching is thus among one of these strategies. The FC approach is thus assumed as one of the new pedagogical models, depending on developing technologies [3] even if such methods have created several challenges in education, especially in medical sciences [4-8].

Some studies have further supported the FC as a pedagogical approach for independent learning [8], which results in more learning compared with other methods [5] and can even produce high levels of satisfaction in learners [6]. Nevertheless, there is evidence on less satisfaction [5] and the same effects as other teaching methods [9]. The results of a review study on nursing education had indicated contradictory results of using the FC on levels of satisfaction, learning rate, and grade point average in students [5, 7]. Existing evidence also leads to the assumption that a pedagogical model, even a new one alone, cannot advance learning, so an integration of several methods should be exercised to create active learning and thinking in learners [10]. It seems that the integration of two new pedagogical methods can cover the weaknesses of each other. In this sense, the NPE, as one of the effectively positive pedagogical methods, is often evaluated by medical students [11], because it is believed that peers are more familiar with their own educational needs and can better understand those of other students and help them learn [12].

Patient safety (PS), as one of the priorities of global health, is an important issue in medical education that requires the use of long-lasting methods of teaching. Accordingly, utilization of pedagogical strategies is a key element in improving attitudes and practices associated with PS. The NPE has been thus recognized formally and informally by many organizations as an effective way to provide PS education [3, 13]. Although most studies have not so far assessed knowledge retention [14-17], their results show that this type of education can have effectiveness in PS [15], improves attitudes towards PS in students [16], and leads to success in medical education programs [17].

Unfortunately, many studies on medical students have demonstrated that they receive insufficient education to increase support capabilities for PS and have even claimed that they lack the necessary knowledge or skills [1]. Since the world of education today has shifted its focus from teaching to learning [18], medical science education including nursing and midwifery requires fundamental changes [19]. A review of the literature shows that new methods of teaching are not also entirely desirable and 
common [20]. For this reason, specialists in education seek to exploit different teaching methods at once [21] to remove their limitations and disadvantages. Therefore, considering the importance of knowledge retention in PS education to nursing and midwifery students and the irreparable harm caused by students' insufficient knowledge of PS, an integration of two new methods of teaching to cover the weaknesses of each other seems of utmost importance. The present study was to compare The Effect of FC by NPE and conventional method on on PS Knowledge Retention in Nursing and Midwifery Students enrolled at Bushehr University of Medical Sciences, Bushehr, Iran.

\section{Methods}

\section{Study design}

This study was a randomized controlled trial (IRCT code: IRCT20090522001930N3, 18/3/2019) with a pretest-posttest and follow-up as well as intervention and control groups. To remove the effects of the pretest in sensitizing the students and preventing damage to the external validity of the study, the Solomon four-group design was utilized. In this sense, the samples were randomly divided into four groups, i.e., two intervention groups and two control groups. Then, only the pretest was administered on one intervention group and one control group, and then all four groups received a posttest/follow up knowledge retention.

\section{Sample Size and Recruitment}

The statistical population included third-semester nursing and midwifery students. To determine the sample size, based on the study by Glade and Chata [22] (2015) and with respect to the mean and standard deviation (SD) scores in the intervention group taught by the intervention and control groups, it was equal to $31.60 \pm 6.84$ and $60.20 \pm 10.36$. Considering the 0.05 type I error (alpha) and the $90 \%$ test power, the sample size was calculated by 10 individuals in each group.

As this sample size was for studies in which the two groups could be compared, it was modified for more than two groups utilizing the sample-size correction formula and ultimately 17 students were determined for each group. As the total number of the students in the classrooms was 92, 23 cases were considered for each group. The samples were then divided into four groups via block randomization. To have an equal proportion of the nursing and midwifery students in each group, they were blocked separately. Since the number of the nursing students was 64 and the midwifery ones were 28, eight 8-part blocks and seven 4-part blocks were considered, respectively. Blocking was performed using the Random Allocation software.

The inclusion criteria in this study were students enrolled in the third semester of nursing and midwifery program, having access to a computer or smartphone, and showing willingness to participate in the research. On the other hand, the exclusion criteria were absenteeism for any reasons, not viewing the educational content, and unwillingness to continue cooperation in the study.

\section{The survey}

As well, a demographic characteristics information sheet and the Patient Safety Knowledge Retention Exam (PSKRE) were used to collect the data.

The demographic characteristics information sheet included items on age, gender, year of admission, being native, place of residence (i.e., dormitory or private home), and field of study.

In order to develop the PSKRE, 70 items were initially prepared and designed based on blueprints and education objectives associated with PS set by the Ministry of Health and Medical Education. Then, to gain scientific credibility, the items were submitted to 10 Faculty members of the School of Nursing and Midwifery affiliated to Bushehr University of Medical Sciences and two experts in the field of PS. Afterwards, the items were reviewed by these Faculty membersand their opinions were implemented. Finally, the items reduced to 32 cases targeting knowledge retention associated with patient safety. 


\section{Procedure}

Upon explaining the research procedure and receiving the informed consent form, the pretests were taken from the intervention group one and the control group one. To avoid information exchange, the control group received the education at first, using the conventional methods (namely, a workshop program lasting three two-hour sessions) by the relevant teacher.

The content of the PS education program was also prepared to be presented to the intervention group by the researchers, based on the standard principles of PS provided by the World Health Organization (WHO) [23], scientific references [24, 25], as well as circulars of the Ministry of Health and Medical Education in Iran[26]. The educational content included information about the importance of patient safety, types of medical errors, causes of medical errors, risk management, patient safety indicators, as well as nine patient safety solutions.

The Microsoft PowerPoint and the Camtasia Studio software were also employed to prepare the educational content and to present it to the intervention group. The content was then uploaded to a website specifically designed for this purpose two weeks before the implementation of the FC by NPE, and the intervention group members were asked to view the full course content within two weeks before the classroom. After browsing the website, the users greeted with a welcome message could open their personal information page through inserting their usernames and passwords. Due to the interactive design of the website, the students of the two intervention groups as users could access it at any time and place via connecting to the Internet with their smartphones, tablets, and personal computers and then view the educational content uploaded on the website.

During the pedagogical intervention, the researchers could check the follow-up status of the course by the students in the intervention group from the management panel of the website in a momentary and up-to-date manner. Accordingly, if necessary, further follow-ups were done to encourage the students to view the educational content through sending messages or making phone calls.

The near-peer (as a Master's student in nursing) also received the necessary training in three sessions of two hours before implementing the FC under the supervision of the relevant educator. To avoid any errors in conveying the educational concepts, the near-peer could lead the classroom in the presence of the educator. The educational content was then presented in the form of three two-hour sessions during one day. Within the FC, the near-peer divided the students into groups of five or six, and the students were then asked to sit next to each other with their counterparts in the same group. The near-peer briefly explained the lesson plan and the learning objectives at the onset of the classroom and summarized the main concepts of the lesson at the end. The standard clinical scenarios related to the concepts were extracted from the book published by the Ministry of Health and Medical Education, entitled as PS [26], prior to the intervention, and then presented in the classroom. Next, the learners were given five minutes to analyze each scenario with all their group members and answer the questions corresponding to each scenario. Afterwards, each group was asked to speak about the scenario and answer the questions, discuss them with the nearpeer and other students during the classroom, and analyze and answer the questions related to the clinical scenarios, to become familiar with the application of theoretical knowledge in clinical practice. As the classroom was over, all the students in four groups were tested, and two months after the classrooms, all four groups received a posttest to assess their knowledge retention. The test items were the same and they were designed by the researchers to evaluate levels of knowledge in all three stages, i.e., before, immediately after, and two months after the intervention. All methods were carried out in accordance with relevant guidelines and regulations.

\section{Data analysis}

To describe the data, descriptive statistics including frequency, mean, and SD were used. The Shapiro-Wilk test was further employed to examine the data distribution. As well, the Kruskal-Wallis test, the Chi-square test, and the Fisher's exact test were utilized to compare the demographic variables between the four groups. Moreover, the paired-samples t-test or the repeated measures analysis of variance (ANOVA) was employed to compare the mean scores in the dependent groups. The independentsamples t-test and the one-way ANOVA were also used for between-group comparisons. The SPSS Statistics software (version 19) was employed for statistical tests and the significance level was considered less than 0.05 in all cases. 


\section{Results}

Since this study was completed using the Solomon four-group design with two control groups as well as two intervention groups, one with pretest and one without pretest, the control group one and the intervention group one (with pretest) and the control group two and the intervention group two (without pretest) were used.

In this study, a total number of 92 nursing and midwifery students (namely, 67 nursing students and 24 midwifery students) participated in four groups of 23 , in the form of two intervention groups and two control groups. Out of the participants in the four intervention and control groups, 10 cases were excluded from the study due to non-participation ((Fig. 1).

The participants included 51 female students (62.2\%) and 31 male counterparts (37.8\%) with a total mean age of $21.23 \pm 1.65$ years. The mean and the SD of the age of the intervention groups one and two were by $20.73 \pm 0.86$ and $21.28 \pm 1.30$ years, respectively. As well, the mean and the SD of the age of the control groups one and two were by $21.75 \pm 2.75$ and $21.22 \pm 0.94$ years, respectively. Moreover, the Kruskal-Wallis test results did not show a statistically significant difference between the four groups in terms of age $\left(x^{2}=3.91 ; p=0.271\right)$. The four groups did not differ with regard to other demographic variables $($ Table 1$)$.

Table 1

Comparison of demographic variables between the four intervention and control groups

\begin{tabular}{|c|c|c|c|c|c|c|c|}
\hline Variable & $\begin{array}{l}\text { Variable } \\
\text { levels }\end{array}$ & $\begin{array}{l}\text { Intervention } \\
1(\%)\end{array}$ & $\begin{array}{l}\text { Intervention } 2 \\
\text { (\%) }\end{array}$ & $\begin{array}{l}\text { Control } \\
1(\%)\end{array}$ & $\begin{array}{l}\text { Control } 2 \\
(\%)\end{array}$ & $\begin{array}{l}\mathrm{X} 2 \text { or } \\
\mathrm{F}^{*}\end{array}$ & $\begin{array}{l}P \\
\text { value }\end{array}$ \\
\hline \multirow[t]{2}{*}{2.758} & \multirow[t]{2}{*}{0.430} & \multirow[t]{2}{*}{ Sex } & Girl & 23.5 & 23.5 & 29.4 & 23.5 \\
\hline & & & Boy & 35.5 & 29.0 & 16.1 & 19.4 \\
\hline \multirow[t]{2}{*}{ Marital status } & Single & 27.6 & 26.3 & 23.7 & 22.4 & \multirow[t]{2}{*}{$0.817^{\star}$} & \multirow[t]{2}{*}{0.146} \\
\hline & Married & 33.3 & 16.7 & 33.3 & 16.7 & & \\
\hline \multirow[t]{2}{*}{ living area } & City & 23.9 & 28.2 & 23.9 & 23.9 & \multirow[t]{2}{*}{$4.834^{\star}$} & \multirow[t]{2}{*}{0.183} \\
\hline & Village & 54.5 & 9.1 & 27.3 & 9.1 & & \\
\hline \multirow[t]{2}{*}{ Indigenous } & Yes & 28.0 & 26.0 & 26.0 & 20.0 & \multirow[t]{2}{*}{0.366} & \multirow[t]{2}{*}{0.947} \\
\hline & No & 28.1 & 25.0 & 21.9 & 25.0 & & \\
\hline \multirow[t]{2}{*}{$\begin{array}{l}\text { Residence while } \\
\text { studying }\end{array}$} & $\begin{array}{l}\text { Private } \\
\text { house }\end{array}$ & 23.1 & 30.8 & 30.8 & 15.4 & \multirow[t]{2}{*}{$0.948^{*}$} & \multirow[t]{2}{*}{0.855} \\
\hline & Dormitory & 29.0 & 24.6 & 23.2 & 23.2 & & \\
\hline \multirow[t]{2}{*}{ Field of Study } & Nursing & 26.2 & 26.2 & 26.2 & 21.3 & \multirow[t]{2}{*}{0.692} & \multirow[t]{2}{*}{0.895} \\
\hline & Midwifery & 33.3 & 23.8 & 19.0 & 23.8 & & \\
\hline
\end{tabular}

The distribution of the pretest scores in both intervention and control groups one as well as in the posttest and the follow-up in all four groups was found normal. The results of the within-group comparisons revealed that the mean score of the PSKRE in the intervention and control groups one was different at three times. The post-hoc test results also established that the mean scores of posttest and follow-up were significantly higher than those of the pretest in the intervention group one ( $\mathrm{p}$-values in both cases were less than 0.001) and the mean score of the follow-up compared with that of the posttest showed a statistically significant descending trend $(p=0.006)$. In the control group one, the posttest mean score $(p<0.001)$ was significantly higher than that of the pretest, but there was no statistically significant difference between the mean scores of the pretest and the follow-up ( $p=$ 0.100). The follow-up mean score was significantly lower than that of the posttest $(p=0.003)$. In intervention group two, the PSKRE mean score in the posttest and the follow-up was not statistically significant. However, the PSKRE mean score in the control group two, the intervention group, and the total control groups in the follow-up was significantly lower than that in the posttest (Table 2). 
Table 2

Intra-group comparison of the average score of safety management by groups

\begin{tabular}{|llllll|}
\hline Group & Pre-test & Post-test & Follow up & \multirow{2}{*}{ t or F* } & P value \\
\cline { 2 - 5 } & Mean \pm SD & Mean \pm SD & Mean \pm SD & & \\
\hline Intervention 1 & $15.60 \pm 1.924$ & $25.17 \pm 3.32$ & $21.60 \pm 3.29$ & $64.889 *$ & $<0.001$ \\
\hline Intervention 2 & - & $24.40 \pm 3.67$ & $23.38 \pm 3.89$ & 1.059 & 0.303 \\
\hline Control 1 & $16.65 \pm 2.10$ & $20.80 \pm 4.16$ & $16.10 \pm 3.55$ & $11.120 *$ & $<0.001$ \\
\hline Control 2 & - & $21.27 \pm 3.86$ & $17.05 \pm 3.33$ & 4.880 & $<0.001$ \\
\hline Total intervention & - & $24.81 \pm 3.47$ & $22.33 \pm 3.60$ & 3.164 & 0.003 \\
\hline Total control & - & $21.03 \pm 3.98$ & $16.55 \pm 3.44$ & 6.001 & $<0.001$ \\
\hline *Report statistics is F value & & & & \\
\hline
\end{tabular}

The results of the between-group comparisons confirmed that the changes in the mean scores from the pretest to the posttest were different between the intervention and control groups one. The intervention group also showed a higher score increase. Furthermore, the changes in the PSKRE mean scores between the pretest and the follow-up were different in both intervention groups one and the control group one, i.e., rising and falling trends in the mean scores in the intervention group and the control group, respectively (Table 3).

Table 3

Comparison of mean changes in patient safety management score before and immediately after the intervention and also before and two months after the intervention between control groups 1 and intervention 1

\begin{tabular}{|c|c|c|c|c|c|c|c|c|c|c|}
\hline \multirow[t]{3}{*}{ Time } & \multirow[t]{3}{*}{ Group } & \multirow{3}{*}{$\begin{array}{l}\text { Average } \\
\text { changes }\end{array}$} & \multirow{3}{*}{$\begin{array}{l}\text { Standard } \\
\text { deviation }\end{array}$} & \multicolumn{4}{|c|}{ Mean difference } & \multirow{3}{*}{$\begin{array}{l}\mathrm{T} \\
\text { statistic }\end{array}$} & \multirow{3}{*}{$\begin{array}{l}\text { Degree } \\
\text { of } \\
\text { freedom }\end{array}$} & \multirow{3}{*}{$\begin{array}{l}P \\
\text { value }\end{array}$} \\
\hline & & & & \multirow[t]{2}{*}{ Average } & \multirow[t]{2}{*}{$\begin{array}{l}\text { Standard } \\
\text { error }\end{array}$} & \multicolumn{2}{|c|}{$\begin{array}{l}\text { Assurance } \\
\text { interval for } \\
\text { mean } \\
\text { difference }\end{array}$} & & & \\
\hline & & & & & & $\begin{array}{l}\text { Low } \\
\text { limit }\end{array}$ & $\begin{array}{l}\text { High } \\
\text { limit }\end{array}$ & & & \\
\hline \multirow{2}{*}{$\begin{array}{l}\text { Post-test } \\
\text { minus pre- } \\
\text { test }\end{array}$} & $\begin{array}{l}\text { Intervention } \\
1\end{array}$ & 9.57 & 2.83 & \multirow[t]{2}{*}{5.41} & \multirow[t]{2}{*}{1.28} & \multirow[t]{2}{*}{8.05} & \multirow[t]{2}{*}{2.77} & \multirow[t]{2}{*}{4.204} & \multirow[t]{2}{*}{41} & \multirow[t]{2}{*}{$<0.001$} \\
\hline & Control 1 & 4.15 & 5.12 & & & & & & & \\
\hline \multirow{2}{*}{$\begin{array}{l}\text { Follow up } \\
\text { minus } \\
\text { before } \\
\text { intervention }\end{array}$} & $\begin{array}{l}\text { Intervention } \\
1\end{array}$ & 6.00 & 4.20 & \multirow[t]{2}{*}{6.55} & \multirow[t]{2}{*}{1.25} & \multirow[t]{2}{*}{9.09} & \multirow[t]{2}{*}{4.01} & \multirow[t]{2}{*}{5.211} & \multirow[t]{2}{*}{41} & \multirow[t]{2}{*}{$<0.001$} \\
\hline & Control 1 & -.55 & 4.01 & & & & & & & \\
\hline
\end{tabular}

The changes in the PSKRE mean scores from the posttest to the follow-up were not statistically significant between the four study groups (Table 4). In addition, the changes in the mean and the SD from the posttest to the follow-up in the two groups of intervention and total control were $2.48 \pm 5.15$ and $4.47 \pm 4.49$, respectively. The two groups did not have a statistically significant difference in terms of changes in their mean scores $(t=1.89 ; p=0.071)$. 
Table 4

Comparison of mean changes in safety management score immediately after and two months after intervention between the four groups

\begin{tabular}{|llllll|}
\hline Time & Group & Average changes & Standard deviation & F & P value \\
\hline Follow minus post-test & Intervention 1 & -3.57 & 4.91 & 1.941 & 0.130 \\
\cline { 2 - 5 } & Intervention 2 & -1.25 & 5.28 & & \\
\cline { 2 - 5 } & Control 1 & -4.70 & 5.38 & \\
\cline { 2 - 5 } & Control 2 & -4.22 & 3.67 & \\
\hline Test performed: one-way analysis of variance & & & & \\
\hline
\end{tabular}

\section{Discussion}

The main purpose of this study was to compare the effects of PS education using the FCA by NPE and the conventional methods on knowledge retention associated with PS in nursing and midwifery students. The study results showed that the integration of the FCA and the NPE compared with the conventional methods had broadened the levels of knowledge in the students in the field of PS. However, PS education through the FCA by NPE was not significantly different from the conventional methods, in terms of their effects on knowledge retention among nursing and midwifery students, two months following the intervention.

The results of the within-group comparisons showed that both FCA by NPE and conventional methods could boost learners' knowledge. The between-group comparison results also demonstrated a greater increase in learning in the group receiving the FCA by NPE and the four-group Solomon design confirmed these findings. It was established that learning in the intervention group was more than that in the control group even in terms of the effects of the pretest.

Limited research has so far examined the integration of the FCA with other methods $[3,27,28]$ and there was no research available, to the best of authors' knowledge, reflecting on the FCA by NPE. Therefore, the study findings were compared with some investigations that had explored the NPE as well as the FCA alone. Accordingly, the study findings were consistent with those by Kim et al. (2019), Shohani et al. (2020), Salman et al. (2020) in the NPE [13, 29, 30], and Rojun Hu et al. (2018), Bao-ju Li et al. (2020), and Tsung Lan Choo et al. (2019) using the FC [19, 31, 32]. However, these findings were not in line with the study by Hatami-Rad et al. and Samantha Son Hoysen et al. (2014) in the NPE [33,34]. Perhaps the reason for the inconsistency of the results was that, an integration of the FC and the NPE education was used in the present study, leading to greater effectiveness of education and a difference between the intervention and the control groups in terms of the PSKE mean scores. It is believed that using a teaching method based on an educational theory alone cannot promote learning, so an integration of pedagogical methods should be used to create active learning thinking in learners [35]. Another point was that, the levels of knowledge in students were evaluated in the present study, while in the mentioned investigations, clinical skills and performance had been appraised. The complexity and the specific difficulties of clinical skills [30] could be thus a reason for the inconsistency of the findings. Further studies could also determine the effects of similar pedagogical interventions on different levels of knowledge.

On the other hand, the present study was not in agreement with the reports by Whillier et al. (2015) and Harrington et al. (2015), using the FC $[7,36]$. In this sense, Whillier et al. (2015) had found that, levels of satisfaction in students as well as their mean scores in terms of knowledge in the FC and structured classrooms instructed by teachers through problem-solving and case study were similar. The reason for the difference could be related to the educational content. In the present study, the PS program was presented through the FC by NPE, since it was one of the most important dimensions of quality of care and any harm to patients was in conflict with the philosophy of health care. In the PS education, the description of natural events and interesting, objective, and tangible scenarios could cause the content not to be presented in a soulless way. Therefore, learners' attention could be more drawn to the educational content, and it could become more comprehensible to them.

Whillier et al., on the other hand, had used the FC to teach neuroanatomy [36]. Although this approach was somewhat selfdirected learning $[37,38]$, it might not be very suitable for biomedical courses and those with heavy content. Of course, the effect 
of new pedagogical methods on different contents needs further studies. The difference between the two studies might be also related to the conventional methods with which the new method was compared. In the study by Whillier et al. (2015) the content was provided to the students on a web-based source before teaching via the conventional methods, while in the present study, the content was provided to the students at the same time as a workshop program through the conventional methods. It is important to note that most of the lessons were taught in the traditional education in the context where this study was conducted (Iran) and there was little use of new methods such as the internet to upload content and the NPE or the FC. This novelty could thus increase the attractiveness of the method and make it more effective. In general, based on the study results, the integration of two new methods of teaching could make the education of PS topics more effective than the conventional methods. The FC is also technology-dependent, and students plan for their learning based on their different learning abilities and styles [39, 40]. This feature, along with the more attractiveness of the method, the bolder role of students in learning, as well as the less stress because of the NPE can be among the reasons for the greater impact of the integrated method of the FC and the NPE. However, these results cannot be generalized to teaching other courses, because it does not mean that integrating the FC and the NPE is necessarily the most effective strategy. Accordingly, it is suggested that enough space and facilities be provided for the use of web-based education, as well as the infrastructure for the practice of modern teaching methods along with the integration of these methods at universities. In addition, the required conditions should be put on the agenda of universities for examining the effect of new methods to determine the most appropriate ones for course contents.

The study findings showed that this pedagogical method had no effect on students' knowledge retention after two months of education compared with the traditional methods. However, the PSKRE mean scores two months after the intervention were still higher in the two intervention groups than the control group, but the drop in the mean scores from the posttest to the follow-up was similar in the four study groups. Javaheri et al. (2018) in their study on the effect of peer education and Graham et al. (2019) and Gu et al. (2020) examining the impact of the FC had further confirmed that the levels of knowledge at the follow-up were higher in the intervention group, which was in line with the present study $[3,39,40]$. These studies had not measured the changes in the mean scores from the posttest to the follow-up, which could indicate a decrease in knowledge over time as a better criterion for assessing retention. The present study revealed that knowledge loss after the posttest was similar in the intervention and control groups. In fact, the higher mean score of the PSKRE follow-up was the output of more learning and a higher knowledge score immediately after the intervention. Accordingly, examining the decline in learning over time could lead to a better and more explicit understanding of the impact of new methods of teaching and the integrated ones and help teachers decide to select the most appropriate methods. Deep learning can further stabilize the acquired knowledge and lead to academic achievement [41]. Therefore, it is important to study knowledge retention in different pedagogical methods. The point is that learning and knowledge retention are part of the issues that should be measured in modern teaching methods and then compared with conventional ones. In addition, students' satisfaction with teaching methods and their attractiveness are among the issues that should be considered when using different pedagogical methods.

Unfortunately, the present study suffered from some limitations, for example, it did not assess student satisfaction, so it is suggested to consider it in future studies. Another limitation of this study was the comparison of a new method integrated with the conventional one, which did not determine whether the integrated method was more effective than the two new methods of the FC and the NPE alone. As with most pedagogical interventions, it is possible to exchange information between the control and intervention groups, as another limitation of this study.

\section{Conclusion}

The findings of the present study showed that the use of the FC by NTP could increase the PSKRE mean scores and thus boost their learning, but, in general, it had no effect on knowledge retention associated with PS in nursing and midwifery students. Given the limited number of studies in this field, it is recommended to conduct further research with larger sample sizes in other courses and disciplines of medical sciences, and additionally examine students' levels of satisfaction with teaching methods.

\section{Abbreviations}


FC: Flipped Classroom, FC by NPE: Flipped Classroom by Near Peer Education, NPE: Near Peer Education, PS: Patient safety, PSKRE: Patient Safety Knowledge Retention exam, RCT: randomized controlled trial, WHO: World Health Organization.

\section{Declarations}

\section{Acknowledgement}

This study was extracted from MS thesis approved. The authors appreciate the faculty members and students for their participations.

\section{Authors 'contributions}

S.P.G, H.V, F.K and R.B designed the study, arranged ethics approval, S.P.G, H.V, R.B, F.H intervened and data collected. R.B analyzed the data. S.P.G drafted the manuscript and R.B prepared tables. All authors read, edited for scientific accuracy, and approved the final manuscript.

\section{Author details}

SPG: MS Student of Nursing, Student Research Committee, Faculty of nursing and midwifery Bushehr University of Medical Sciences, Bushehr, Iran. FK: PhD of Medical Education, Nursing and Midwifery Faculty. Bushehr University of Medical Sciences. RB: PhD of Reproductive Health, Department of Midwifery, Nursing and Midwifery Faculty. Bushehr University of Medical Sciences. FH: MS in Nursing, Nursing and Midwifery Faculty. Bushehr University of Medical Sciences. HV: PhD of Nursing, Department of Nursing and Midwifery Faculty. Bushehr University of Medical Sciences, Salmanefarsi Blvd, Bushehr. Iran.

\section{Funding}

This research was funded by Bushehr University of Medical Sciences.

\section{Availability of data and materials}

The anonymized datasets used and/or analyzed during the current study are available from the corresponding author on reasonable request.

\section{Ethics approval and consent to participate}

This paper is extracted from a master's degree thesis of the Faculty of Nursing and Midwifery of Bushehr University of Medical Sciences, Bushehr, Iran; which was approved in 2018 and was Research Ethics Committee (Code: 1397.128.IR.BPUMS.REC) and IRCT code )IRCT20090522001930N3 ) in 18/3/2019. A written consent was further obtained from all the study samples.

\section{Competing interests}

The authors report no conflicts of interest in this work.

\section{References}

1. Mostafazadeh F, Asadzadeh-Monir F, Rostamnejad M. Rhostamneghad M Methods of patient safety education for Medical group students. Iranian Journal of Obstetrics and Gynecology. 2103;8(1):23-29. 
2. Ranjbar K, Soltani F, Mousavi nassab M, Masoudi A, Ayatollahi SA. Comparison of the Impact of Traditional and Multimedia Independent Teaching Methods on Nursing Students`Skills in Administrating Medication. Iranian Journal of Medical Education. 2003;9:35-43.

3. Gu M, Sok SR. Effects of Simulation Practicum Using Flipped Learning for Korean Nursing Students. International Journal of Environmental Research and Public Health. 2020;17(18):6829. https://doi.org/10.3390/ijerph17186829.

4. Karimi Monaghi H, Rad M, Bakhshi M. Do the New Methods of Teaching in Medical Education have Adequate Efficacy?: A Systematic Review. Strides in Development of Medical Education. 2013;10(3):153-162.

5. Missildine K, Fountain R, Summers L, Gosselin K. Flipping the classroom to improve student performance and satisfaction. Journaln of Nursing Education.2013;52(10):597-599. https://doi.org/10.3928/01484834-20130919-03.

6. Mikkelsen TR. Nursing students' experiences, perceptions and behavior in a flipped-classroom anatomy and physiology course. Journal of Nursing Education and Practice. 2015;5(10):28. https://doi.org/10.5430/jnep.v5n10p28.

7. Harrington SA, Bosch MV, Schoofs N, Beel-Bates C, Anderson K. Quantitative outcomes for nursing students in a flipped classroom. Nursing Education Perspectives. 2015;36(3):179-181. https://doi.org/10.5480/13-1255.

8. Enfield J. Looking at the impact of the flipped classroom model of instruction on undergraduate multimedia students at CSUN. TechTrends. 2013;57(6):14-27.

9. Overmyer GR. The flipped classroom model for college algebra: Effects on student achievement. In. Colorado State University. 2014.

10. Karimi Monaghi H, Mostafazadeh SM. Blended Learning and Its Effectiveness in Nursing Education: Review. Reducational development of jundishapur. 2019;10(1):29-40.

11. Salehi S, Safavi M, Mashoof S, Parchebafieh S, Fesharaki M. Effects of peer education on clinical skills in nursing students, including interns and trainees. Medical Science Journal of Islamic Azad Univesity-Tehran Medical Branch. 2016;26(1):36-45.

12. Adib-Hajbaghery M, Motaharian ES. Teaching through Near-Peer Method in Medical Education: A Systematic Review. Iranian Journal of Medical Education. 2016;16:366-378.

13. Shohani M, Moradi S, Khorshidi A, Jalilian M. Comparison of the effect of" near-peer" teaching and trainer on hand hygiene in first year nursing students of llam University of Medical Sciences. Journal of Advanced Pharmacy Education \& Research| Jan-Mar. 2020;10(1):83-87.

14. Kimyai S, Jafari Navimipour E, Mohammadi N. The Effect of Peer Education on Practical Skills Training of Dentistry Students in Restorative Preclinic. Iranian Journal of Medical Education. 2011;11(4):418-424.

15. Jackson TA, Evans DJ. Can medical students teach? A near-peer-led teaching program for year 1 students. Adv Physiol Educ. 2012;36(3):192-196. https://doi.org/10.1152/advan.00035.2012.

16. Bahadorani M, Yousefy AR, Changiz T. The effectiveness of three methods of teaching medline to medical students: online, face to face and combined educational methods. Iranian Journal of Medical Education. 2006;6(2):35-43.

17. norozi hm, mohsenizadeh sm, jafary suny h, ebrahimzadeh s. The Effect of Teaching Uning a Blend of Collaborative and Mastery of Learning Models, on Learning of Vital Signs: An Experiment onNursing and Operation Room Students of Mashhad University of Medical Sciences. Iranian Journal of Medical Education. 2011;11(5):544-553.

18. Bagheri M, Joshaghan Nejhad F. Effect Of Flipped Learning Method On Students' Self- Directed Learning Readiness And Learning In The Computer Basics Course. Curriculum technology. 2016;1(1):49-61. https://doi.org/10.22077/jct.2016.662.

19. Li B-Z, Cao N-W, Ren C-X, Chu X-J. Flipped classroom improves nursing students' theoretical learning in China: A metaanalysis. PloS one. 2020;15(8):e0237926. https://doi.org/10.1371/journal.pone.0237926.

20. Egeland I. Knowledge retention in organizations. A literature review and case study exploring how organizations can transfer and retain knowledge to mitigate knowledge loss when older employees retire. In. University of Stavanger Norway. 2017.

21. Sadeghi R, sedaghat $\mathrm{mm}$, Shaahmadi f. Comparison of the effect of lecture and blended teaching methods on students' learning and satisfaction. Journal of advances in medical education \& professionalism. 2014;2(4):146-150.

22. Charles-Ogan G, Williams C. Flipped classroom versus a conventional classroom in the learning of mathematics. In Proceedings of South Africa International Conference on Educational Technologies. 2015;3(6):71-77. 
23. WHO Guidelines on Hand Hygiene in health care, The burden of Health caer-associated infection. 2009;6-7.

24. Walton M, Woodward H, Van Staalduinen S, Lemer C, Greaves F, Noble D, Ellis B, Donaldson L, Barraclough B. The WHO patient safety curriculum guide for medical schools. BMJ Quality \& Safety. 2010;19(6):542-

6. https://doi.org/10.1136/qshc.2009.036970.

25. Thompson DA, Cowan J, Holzmueller C. Planning and implementing a systems-based patient safety curriculum in medical education. American Journal of Medical Quality. 2008; 23(4): 271-278. https://doi.org/10.1177/1062860608317763.

26. Mohammad A. Patient safety curriculum. kak khiyal. 2016.

27. Halasa S, Abusalim N, Rayyan M, Constantino RE, Nassar O, Amre H, Sharab M, Qadri I. Comparing student achievement in traditional learning with a combination of blended and flipped learning. Nursing Open. 2020;7(4):1129-1138. https://doi.org/10.1002/nop2.492

28. Ding C, Li S, Chen B. Effectiveness of flipped classroom combined with team-, case-, lecture-and evidence-based learning on ophthalmology teaching for eight-year program students. BMC medical education. 2019;19:419. https://doi.org/10.1186/s12909-019-1861-y.

29. Kim YM, Yoon YS, Hong HC, Min A. Effects of a patient safety course using a flipped classroom approach among undergraduate nursing students: A quasi-experimental study. Nurse Education Today. 2019;79:180-187. https://doi.org/10.1016/j.nedt.2019.05.033.

30. Guraya SY, Abdalla ME. Determining the effectiveness of peer-assisted learning in medical education: A systemic review and meta-analysis. Journal of Taibah University Medical Sciences. 2020;30(15):177-184. https://doi.org/10.1016/j.tumed.2020.05.002.

31. Chu T-L, Wang J, Monrouxe L, Sung Y-Ch. The effects of the flipped classroom in teaching evidence based nursing: A quasiexperimental study. PLoS One. 2019;14(1):e0210606. https://doi.org/10.1371/journal.pone.0210606.

32. Hu R, Gao H, Ye Y, Ni Zh, Jiang N, Jiang X. Effectiveness of flipped classrooms in Chinese baccalaureate nursing education: A meta-analysis of randomized controlled trials. International Journal of nursing studies. 2018; 79: 94-103. https://doi.org/10.1016/j.jijnurstu.2017.11.012.

33. Hatami Rad R, Yamani N, Ehsanpour S. Effects of Teacher-Centered Teaching and Peer Teaching Methods on Improving Some Clinical Skills of Midwifery Students: A Comparative Study. Iranian Journal of Medical Education. 2017;17:335-343.

34. Sevenhuysen S, Skinner EH, Farlie MK, Raitman L, Nickson W, Keating JL, Maloney S, Molloy E, Haines TP. Educators and students prefer traditional clinical education to a peer-assisted learning model, despite similar student performance outcomes: a randomised trial. Journal of physiotherapy. 2014;60(4):209-216. https://doi.org/10.1016/j.jphys.2014.09.004.

35. Deubel P. An investigation of behaviorist and cognitive approaches to instructional multimedia design. Journal of educational multimedia and hypermedia. 2003;12(1):63-90.

36. Whillier S, Lystad RP. No differences in grades or level of satisfaction in a flipped classroom for neuroanatomy. Journal of Chiropractic Education. 2015;29(2):127-133. https://doi.org/10.7899/jce-14-28.

37. Liu WI, Edwards H, Courtney M. Review of continuing professional education in case management for nurses. Nurse Educ Today. 2009;29(5):488-492. https://doi.org/10.1016/j.nedt.2008.11.004.

38. Haghani F, Rezaei H, baeigzade A, Eghbali B. Flipped Classroom: A Pedagogical Method. Iranian Journal of Medical Education. 2016;16(11):104-119.

39. Graham KL, Cohen A, Reynolds EE, Huang GC. Effect of a flipped classroom on knowledge acquisition and retention in an internal medicine residency program. Journal of Graduate Medical Education. 2019;11(1):92-97. https://doi.org/10.4300/jgme-d-18-00536.1.

40. Javaheri Arasteh A, Najafi Ghezeljeh T, Haghani S. Effects of Peer-assisted Education on the Knowledge and Performance of Nursing Students in Basic Cardiopulmonary Resuscitation. Iran Journal of Nursing. 2018;31(115):6-19. https://doi.org/10.29252/ijn.31.115.6.

41. Abdulghani HM, Al-Drees AA, Khalil MS, Ahmad F, Ponnamperuma, G, Amin, Z. What factors determine academic achievement in high achieving undergraduate medical students? A qualitative study. Med Teach. 2014;36:43-48.

Page $11 / 12$ 


\section{Figures}

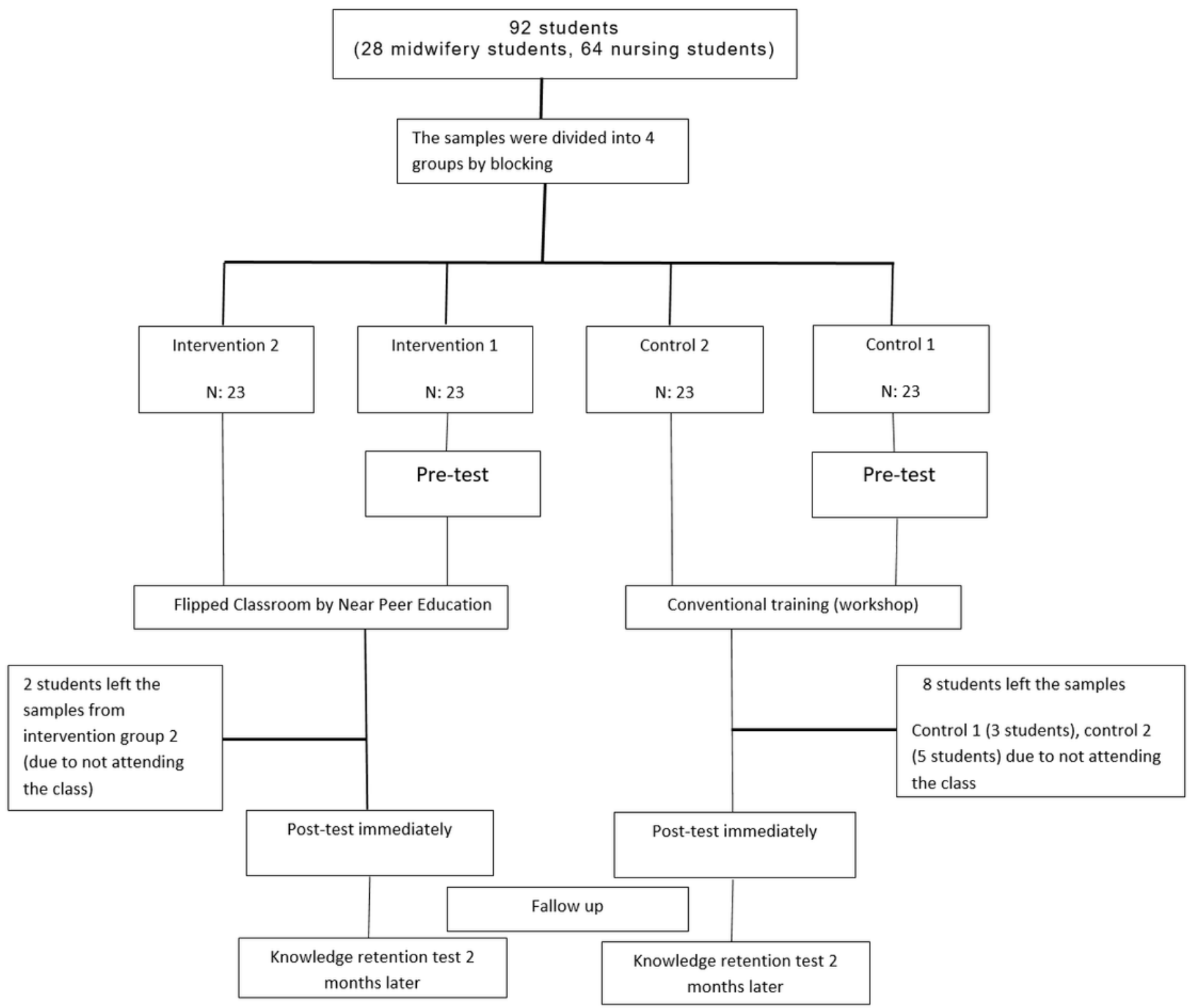

Figure 1

The Study Flow Diagram 